\title{
PRESCRIÇÃO INTERCORRENTE E A INEXISTÊNCIA DE CONDENAÇÃO EM HONORÁRIOS ADVOCATÍCIOS CONTRA A FAZENDA PÚBLICA
}

\author{
INTERVENING STATUTE OF LIMITATIONS AND THE ABSENCE OF FEES \\ CONDEMNATION AGAINST THE TAX AUTHORITY
}

Recebimento em 09/09/2020

Felipe Viana de Araújo Duque ${ }^{1}$

Aceito em 12/10/2020

\section{RESUMO}

Esse artigo tem por objetivo analisar o fenômeno da prescrição intercorrente na execução fiscal, perquirindo sobre o princípio da causalidade na condenação em honorários advocatícios da Fazenda Pública, com o intuito de refletir e estimular medidas como o reconhecimento de ofício da prescrição intercorrente pelos Entes Públicos, impactando de sobremaneira na redução de litigiosidade e cooperação para reduzir a alta taxa de congestionamento do Poder Judiciário.

Palavras-chave: Prescrição intercorrente; honorários advocatícios; princípio da causalidade.

\section{ABSTRACT}

The purpose of this article was to analyze the intercurrent precursor on tax execution, investigating the principle of causality in the condemnation of attorneys' fees in the Public Treasury, with the purpose of reflecting and disseminating measures such as the recognition of the award of intercurrent prescription by Public Entities, Impossibility to reduce and cooperate to reduce the congestion charge of the Judiciary.

Keywords: Intercurrent prescription; Advocative hours; principle of causality.

\section{INTRODUÇÃO}

Nos últimos anos, a discussão sobre a constituição e cobrança do crédito tributário tem se mostrado necessário frente a clara falência do seu modelo. Ou seja, há um enorme e desequilibrado contencioso tributário brasileiro de maneira que se torna imperativo

\footnotetext{
${ }^{1}$ Mestre em Direito Político e Econômico na Universidade Presbiteriana Mackenzie (2019). Cursou Justice em Harvard University (2019). Pós-graduado em Direito Processual Tributário (2016) e em Direito Civil (2015). Bacharel em Direito pela Universidade Católica de Pernambuco (2010 - 2013), com conclusão pelo regime de aproveitamento de estudos e conhecimentos extraordinários (Art. $47 \S 2^{\circ}$ da Lei 9.394/96). É professor visitante da Faculdade Legale-SP e professor convidado do programa Saber Direito da TV Justiça (STF). É membro do Grupo de Pesquisa Estado e Economia no Brasil ligado ao Programa de Pós-Graduação em Direito Político e Econômico. Atualmente é Procurador da Fazenda Nacional. Ex-Assessor de Desembargador no Tribunal de Justiça de Pernambuco
} 
umamacrovisão do crédito tributário perantea realidade no cotidiano jurídico, com a necessidade de estudo da efetividade edos seus dados, principalmente diante do impacto do número de execuções fiscais no âmbito do Poder Judiciário.

Nesse panorama, cumpre ressaltar que com base nos dados do Conselho Nacional de Justiça, o último relatório divulgado “Justiça em Números 2020”, o número dos processos de execução fiscal representam, aproximadamente, $39 \%$ do total de casos pendentes no Poder Judiciário $70 \%$ das execuções pendentes, tendo uma elevada taxa de congestionamento de $86,9 \%$, contribuindo de sobremaneira para a chamada "Crise da Justiça"2 conforme delineada por Antônio Sebastião De Lima (2006), isto é, um sobrecarregamento da esfera judicial na resolução de todos os litígios, sendo urgente a abertura para meios adequados (alternativos) de resolução de conflitos (CNJ, 2019, p.155):

“(...)Historicamente as execuções fiscais têm sido apontadas como o principal fator de morosidade do Poder Judiciário. O executivo fiscal chega a juízo depois que as tentativas de recuperação do crédito tributário se frustraram na via administrativa, provocando sua inscrição na dívida ativa. Dessa forma, o processo judicial acaba por repetir etapas e providências de localização do devedor ou patrimônio capaz de satisfazer o crédito tributário já adotadas, sem sucesso, pela administração fazendária ou pelo conselho de fiscalização profissional. Desse modo, acabam chegando ao Judiciário títulos de dívidas antigas e, por consequência, com menor probabilidade de recuperação(...)”

Outrossim, há quem entenda, como Marcelo Franco (2011) que a crise da justiça seria como um problema de tal magnitude que seria um fator cultural e também administrativogerencial, isto porque, o Brasil, com seus 92 tribunais, possui o maior sistema Judiciário do mundo (BRITO; FERNANDES, 2020).

Diante disso, surge a importância de estimular o reconhecimento pela Fazenda Pública de ofício dos processos que foram atingidos pela prescrição intercorrente, especialmente em virtudedo julgamento do Recurso Especial n. 1.340.553/RS, julgado pela sistemática do recurso repetitivo pelo Superior Tribunal de Justiça (STJ) que apresenta potencial de impacto em cerca de 27 milhões de processos ${ }^{3}$, em que se divulgou teses quanto ao termo inicial do prazo de

\footnotetext{
${ }^{2}$ DE LIMA, Antônio Sebastião. Crise da Justiça. Revista da EMERJ, v.9, n.36, 2006. Disponível em: https://www.emerj.tjrj.jus.br/revistaemerj_online/edicoes/revista36/revista36_271.pdf. Acesso em: 09 set. 2020.

${ }^{3}$ Nessa perspectiva, divulgou-se que o STJ definiu as teses sobre prescrição intercorrente que afetaria mais de 27 milhões de processos. Disponível em: https://www.migalhas.com.br/quentes/287404/stj-define-tese-sobreprescricao-intercorrente-que-afetara-mais-de-27-milhoes-de-processos.Acesso em:12 out. 2020.
} 
prescrição intercorrente, bem como quais atos são aptos para a interrupção do prazo prescricional pondo fim a intensa divergência jurisprudencial.

Não obstante, em que pese tenha sido concluído o julgamento no mérito, houve uma omissão substancial que, apesar de ter sido suscitado em sede de Embargos de Declaração pela União, não houve acolhimento para sua apreciação, isto porque, afinal: como se dará a condenação dos honorários advocatícios quando há o reconhecimento de ofício por parte da Fazenda Pública da prescrição intercorrente?

O intuito deste trabalho, diante de tal análise do instituto da prescrição intercorrente, passa pela necessidade de visualização do fenômeno, bem como da patente necessidade de reflexão do sistema de cobrança dos créditos públicos diante do acervo judicial das execuções fiscais.

\section{BREVES ASPECTOSDA JUSTIÇA FISCAL ATRAVÉS DA EXECUÇÃO FISCAL}

De início, é importante destrinchar que a execução fiscal é uma ação judicial proposta pela Fazenda Pública (União, Estados, DF, Municípios e suas respectivas autarquias e fundações) para cobrar do devedor créditos (tributários ou não tributários) que estão inscritos em dívida ativa.

Em termos gerais, custa salientar que Thomas Piketty $(2014$, p.493) ensina que a tributação seria primordialmente um tema político e não uma questão técnica, eis que sem a arrecadação dos tributos, não há arcabouço suficiente para um destino comum na sociedade e não existe uma ação coletiva organizada. Tanto é assim, que ao entorno de uma relevante questão política há quase sempre uma importante modificação fiscal,

Nesses termos, a tributação apresenta um valor social significadamente instrumental, sendo Política e Direito Tributário sistemas que convergem no conceito de matriz tributária, definível como as escolhas feitas em um determinado momento histórico no campo das ações sociais, no que diz respeito ao fenômeno tributário(GASSEN, 2012, p. 32).

Diante desse quadro, houve acolhimento pelo Supremo Tribunal Federal, que existe no Brasil um verdadeiro "dever fundamental de pagar tributos", constitucionalmente imposto ao 
sujeito passivo. Inclusive, o Min. Gilmar Mendes reconheceu expressamente no seu voto na Ação Direta de Inconstitucionalidade número 1055/DF:

O Estado brasileiro baseia-se em receitas tributárias. Um texto constitucional como o nosso, pródigo na concessão de direitos sociais e na promessa de prestações estatais aos cidadãos, deve oferecer instrumentos suficientes para que possa fazer frente às inevitáveis despesas que a efetivação dos direitos sociais requer. $\mathrm{O}$ tributo é esse instrumento. Considera-se, portanto, a existência de um dever fundamental de pagar impostos. No caso da Constituição, esse dever está expresso no $\S 1^{\circ}$ do art. 145

Percebe-se a importância ímpar do dever fundamental de pagar tributos, que custeiam a estrutura estatal através desses recursos arrecadados, garantindo a prestação de direitos à sociedade. Assim, assevera Leandro Paulsen (2017, p.173):

\begin{abstract}
Aliás, resta clara a concepção da tributação como instrumento da sociedade quando são elencados os direitos fundamentais e sociais e estruturado o estado para que mantenha instituições capazes de proclamar, promover e assegurar tais direitos. Não há mesmo como conceber a liberdade de expressão, a inviolabilidade da intimidade e da vida privada, o exercício do direito de propriedade, a garantia de igualdade, a livre iniciativa, a liberdade de manifestação do pensamento, a livre locomoção e, sobretudo, a ampla gama de direitos sociais, senão no bojo de um Estado Democrático de Direito, Social e Tributário.
\end{abstract}

Nesses termos, a arrecadação tributária não pode ser vista como uma mera obrigação tributária principal, mas sim como uma condição essencial de haver o financiamento dos direitos fundamentais em um Estado Fiscal (MURPHY; NAGEL, 2005, p.57):

Os impostos fazem parte dessa estrutura, mas não podem ser avaliados somente como exigências legais que o Estado impõe aos indivíduos; têm de ser considerados também como contribuições à estrutura dentro da qual todos esses indivíduos vivem. Em última análise, a questão da legitimidade política resumese ao seguinte: dentro de qual estrutura todos nós consideramos moralmente aceitável viver? É a essa questão que se devem aplicar os valores como os da liberdade, responsabilidade, igualdade, eficiência e bem-estar

Inclusive, na doutrina de Sunstein e Holmes (2012,p. 38), percebe-se a importância do Estado como precursora aos direitos, isto é, os direitos seriam interesses que receberiam uma proteção jurídica, pois conseguem garantir a existência da comunidade politicamente organizado.

De tal modo, se há uma falta de efetividade da execução fiscal seja pelo arcabouço jurídico complexo, seja pela Crise da Justiça multifacetada por um acervo Judicial surpreendente, 
esse reflexo também contribui para a ausência de uma cidadania tributária, uma vez que prejudicará a arrecadação e o Estado não possuirá condições de realizar a moderna redistribuição de riqueza ${ }^{4}$, bem como influencia no aumento da concentração de capital, tendo em vista a regressividade da carga tributária em relação aos mais pobres ${ }^{5}$.

\section{ASPECTOS FUNDAMENTAIS DA PRESCRIÇÃO INTERCORRENTE NO ÂMBITO DO SUPERIOR TRIBUNAL DE JUSTIÇA}

De maneira objetiva, a execução se satisfaz normalmente, com o pagamento da dívida ou com a penhora de bens. Porém, pode ser que no curso do processo aconteça algum imprevisto, como a não localização do devedor, ou de bens sujeitos à penhora.

Dessa forma, a prescrição intercorrente fulmina o crédito durante o processo judicial, extinguindo o direito de buscar satisfação do crédito judicialmente.De acordo com o doutrinador e professor Alexandre Freitas Câmara (2016, p.364):

(...) A prescrição intercorrente é um fenômeno análogo à prescrição stricto sensu, mas que desta se diferencia por ocorrer quando o processo já está em curso (não tendo, pois, havido o decurso do prazo prescricional sem que o titular do direito lesado tenha ajuizado sua demanda, o que caracterizaria a prescrição propriamente dita). Assim, paralisado o procedimento executivo nos exatos termos previstos nos $\S \S 1$ o e 4 o do art. 921, configurar-se-á a prescrição intercorrente, e o exequente se verá privado de seu crédito em razão do decurso do tempo, pouco importando se o procedimento executivo teve início com base em título executivo judicial ou extrajudicial. (FPPC, enunciado 194)

Assim, a prescrição intercorrente se diferencia da prescrição comum, tendo em vista que acontece depois de entrado judicialmente com o processo (interposição da execução fiscal), assim ela pode incidir tanto nos processos de execução que estão em curso quanto no cumprimento de sentença. Já a prescrição comum, ocorre antes de se entrar judicialmente com o processo, isto é, o credor não pode seu direito no poder judiciário para que este seja este cumprido ${ }^{6}$.

\footnotetext{
${ }^{4}$ A moderna redistribuição significa a transferência de riqueza pelo financiamento de serviços públicos e substitutos de renda que garantem aproximadamente igualdade de acesso para todos, sobretudo em áreas de saúde, educação e previdência. (PIKETTY, 2014, p. 479).

${ }^{5}$ No que tange a carga tributária, verifica-se que os mais ricos são menos onerados do que os pobres. A regressividade também é perceptível pela maior representação dos impostos indiretos na carga tributária brasileira. Vide: CONSELHO DE DESENVOLVIMENTO ECONÔMICO E SOCIAL, 2011, p. 22).

${ }^{6}$ Torna-se relevante fazer a distinção que no direito civil, o crédito atingido pela prescrição perde apenas a
} 
Em breve síntese, pode-se definir o fenômeno da prescrição intercorrente como aquele que ocorre durante o processo judicial, em virtude da demoraem se prolatar uma decisão satisfativa, pondo fim à causa. No âmbito da execução fiscal, o procedimento foi regulamentado pelo art.40 da Lei 6.830/1980, bem como houve disposição no art. 921 do Código de processo Civil de 2015.

Nas palavras do Min. Luís Felipe Salomão nos autos do REsp n. 1.620.919/PR e exMinistra do Eliana Calmon do Superior Tribunal de Justiça no REsp 1.128.099/RO, respectivamente:

A prescrição intercorrente ocorre no curso do processo e em razão da conduta do autor que, ao não prosseguir com o andamento regular ao feito, se queda inerte, deixando de atuar para que a demanda caminhe em direção ao fim colimado.

(...)resultante de construção doutrinária e jurisprudencial para punir a negligência do titular de direito e também para prestigiar o princípio da segurança jurídica, que não se coaduna com a eternização de pendência administrativas ou judiciais(...)

Repise-se, torna-se importante distinguir da prescrição ordinária, isto porque, esta consiste na perda do direito de a Fazenda Pública ajuizar a execução fiscal contra o contribuinte cobrando o crédito tributário. Dessa forma, ocorre antes do ajuizamento da execução fiscal.De outro lado, a prescrição intercorrente ocorre durante a tramitação da execução fiscal.

Dessa forma, apenas quando interrompida a prescrição ordinária (atualmente, pelo despacho do juiz que retroage à data da citação - art.239 § $1^{\circ}$ do CPC) é que passa a fluir, no curso do processo executivo e diante da inércia da Fazenda Pública credora, a prescrição intercorrente, no mesmo prazo previsto em lei para a prescrição ordinária.

Em outras palavras, reconhece-se a relevância do tema enquanto instituto destinado a impedir a eternização dos conflitos, servindo de relevante instrumento de segurançajurídica e, inclusive, importante do ponto de vista da racionalidade e economicidade para o Estado, eis que demandas eternas destinadas ao fracasso apenas importariam em custos desnecessários, 
porquanto a recuperabilidade do créditoseria inversamente proporcional ao decurso do tempo (INSTITUTO DE PESQUISA ECONÔMICA APLICADA, 2011).

Em outras palavras, a razão prática para a criação do instituto está em evitar a suspensão sem fim do processo diante da não localização do devedor ou de bens penhoráveis, com fundamento no princípio da segurança jurídica.

Dessa forma, reconhecer e buscar diligentemente créditos que foram afetados pela prescrição intercorrente diminuiria de imediato a alta taxa de congestionamento, cerca de $86 \%$ dos processos de execução fiscal, bem como o número de processos judiciais pendentes, diminuindo a morosidade da justiça.

Delimita-se que na medida em que não há mais atos úteis no sentido da localização de bens do devedor, o processo executivo está fadado ao insucesso e virtualmente impossibilitado de alcançar o seu escopo - a satisfação da execução.

Nesse escopo, em análise da jurisprudência do STJ extraem-se os dois requisitos gerais para a incidência da prescrição intercorrente: a) fluência do prazo prescricional no curso do processo executivo após interrompida a prescrição ordinária; b) a inércia censurável da Fazenda Pública quanto à adoção de medidas efetivas à localização do devedor ou à localização de bens penhoráveis (condições alternativas);

Logo, não havendo a citação de qualquer devedor (o que seria apenas marco interruptivo da prescrição) e/ou não sendo encontrados bens sobre os quais possa recair a penhora (o que permitiria o fim da inércia processual), inicia-se o procedimento previsto no art. 40 da Lei n. 6.830/80 e o respectivo prazo prescricional (variará de acordo com a natureza do crédito exequendo) ao fim do qual restará prescrito o crédito fiscal.

No emblemático recurso repetitivo julgado pela $1^{\text {a }}$ Seção do STJ, REsp 1.340.553-RS, ficarem delineados as teses relevantíssimas com possibilidade de aplicação em 27 milhões de processos judiciais pendentes, conforme ementa divulgada pelo Relator Min. Mauro Campbell Marques em 16/10/2018: 


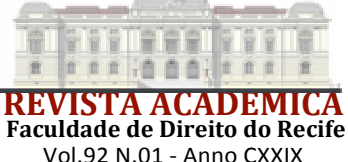

...4. Teses julgadas para efeito dos arts. 1.036 e seguintes do CPC/2015 (art. 543-C, do CPC/1973): 4.1.) O prazo de 1 (um) ano de suspensão do processo e do respectivo prazo prescricional previsto no art. $40, \S \S 1^{\circ}$ e $2^{\circ}$ da Lei $n$. 6.830/80 - LEF tem início automaticamente na data da ciência da Fazenda Pública a respeito da não localização do devedor ou da inexistência de bens penhoráveis no endereço fornecido, havendo, sem prejuízo dessa contagem automática, o dever de o magistrado declarar ter ocorrido a suspensão da execução; 4.1.1.) Sem prejuízo do disposto no item 4.1., nos casos de execução fiscal para cobrança de dívida ativa de natureza tributária (cujo despacho ordenador da citação tenha sido proferido antes da vigência da Lei Complementar n. 118/2005), depois da citação válida, ainda que editalícia, logo após a primeira tentativa infrutífera de localização de bens penhoráveis, o Juiz declarará suspensa a execução.

4.1.2.) Sem prejuízo do disposto no item 4.1., em se tratando de execução fiscal para cobrança de dívida ativa de natureza tributária (cujo despacho ordenador da citação tenha sido proferido na vigência da Lei Complementar n. 118/2005) e de qualquer dívida ativa de natureza não tributária, logo após a primeira tentativa frustrada de citação do devedor ou de localização de bens penhoráveis, o Juiz declarará suspensa a execução.

4.2.) Havendo ou não petição da Fazenda Pública e havendo ou não pronunciamento judicial nesse sentido, findo o prazo de 1 (um) ano de suspensão inicia-se automaticamente o prazo prescricional aplicável (de acordo com a natureza do crédito exequendo) durante o qual o processo deveria estar arquivado sem baixa na distribuição, na forma do art. $40, \S \S 2^{\circ}, 3^{\circ}$ e $4^{\circ}$ da Lei $n$. 6.830/80 - LEF, findo o qual o Juiz, depois de ouvida a Fazenda Pública, poderá, de ofício, reconhecer a prescrição intercorrente e decretá-la de imediato; 4.3.) A efetiva constrição patrimonial e a efetiva citação (ainda que por edital) são aptas a interromper o curso da prescrição intercorrente, não bastando para tal o mero peticionamento em juízo, requerendo, v.g., a feitura da penhora sobre ativos financeiros ou sobre outros bens. Os requerimentos feitos pelo exequente, dentro da soma do prazo máximo de 1 (um) ano de suspensão mais o prazo de prescrição aplicável (de acordo com a natureza do crédito exequendo) deverão ser processados, ainda que para além da soma desses dois prazos, pois, citados (ainda que por edital) os devedores e penhorados os bens, a qualquer tempo mesmo depois de escoados os referidos prazos -, considera-se interrompida a prescrição intercorrente, retroativamente, na data do protocolo da petição que requereu a providência frutífera.

4.4.) A Fazenda Pública, em sua primeira oportunidade de falar nos autos (art. 245 do $\mathrm{CPC} / 73$, correspondente ao art. 278 do $\mathrm{CPC} / 2015$ ), ao alegar nulidade pela falta de qualquer intimação dentro do procedimento do art. 40 da LEF, deverá demonstrar o prejuízo que sofreu (exceto a falta da intimação que constitui o termo inicial - 4.1., onde o prejuízo é presumido), por exemplo, deverá demonstrar a ocorrência de qualquer causa interruptiva ou suspensiva da prescrição.

4.5.) O magistrado, ao reconhecer a prescrição intercorrente, deverá fundamentar o ato judicial por meio da delimitação dos marcos legais que foram aplicados na contagem do respectivo prazo, inclusive quanto ao período em que a execução ficou suspensa.

5. Recurso especial não provido. Acórdão submetido ao regime dos arts. $1.036 \mathrm{e}$ seguintes do CPC/2015 (CPC, 1973, art. 543-C).

Em síntese, restou decidido que no primeiro momento em que constatada a não localização do devedor pelo oficial de justiça e/ou ausência de bens e cientificada a Fazenda 
Pública, iniciará automaticamente o prazo de suspensão de 1 (um) ano, somando-se em seguida o prazo de 5 (cinco) anos, de que trata o art. 40 da LEF (CAVALCANTE, 2018).

Em segundo lugar, apenas a efetiva constrição patrimonial e a efetiva citação (ainda que por edital) são aptas a interromper o curso da prescrição intercorrente, independentemente da manutenção da penhora ou do sucesso do leilão. De outro lado, considera-se interrompida a prescrição intercorrente, retroativamente, na data do protocolo da petição que requereu a providência frutífera.

Noutros termos, decidiu-se, basicamente, que o termo inicial da prescrição intercorrente se dá com uma condição objetiva, seja a não localização de bens, ou a ausência de citação do devedor, de modo que, conforme o ministro Relator ressaltou, nem a Procuradoria, nem o Juiz são os senhores do processo, no sentido de controlar o prazo prescricional.

Logo, apenas atos constritivos seriam suficientes para interromper a contagem do prazo, demonstrando, portanto, que os requisitos alternativos não dependem de mero peticionamento da Fazenda Pública, nem sequer mero despacho pelo juiz para inaugurar o prazo do art. 40 da LEF.

Entretanto, não se discutiu, efetivamente, de quem seria a responsabilidade para arcar comos honorários sucumbenciais quando houvesse o reconhecimento da prescrição intercorrente pelo Magistrado através de uma sentença ou até mesmo o reconhecimento de ofício pela Administração Pública.

Nessa linha, torna-se imperioso o aprofundamento dessa discussão, seja em razão do caráter multiplicador, seja na patente necessidade de se estudar o princípio da causalidade diante das ações de execução fiscal.

\section{DA IMPOSSIBILIDADE DE CONDENAÇÃO DA FAZENDA PÚBLICA EM HONORÁRIOS ADVOCATÍCIOS QUANDO HOUVER RECONHECIMENTO DE OFÍCIO}


O cerne do presente artigo é demonstrar que haveria uma impossibilidade de condenação em honorários advocatícios nos feitos em que haja um reconhecimento de ofício do atingimento de um crédito público fulminado pela prescrição intercorrente.

Nessa linha, suponha uma situação hipotética em que a Fazenda Nacional propôs uma execução fiscal em face do devedor, em que houve adevida citação, mas não encontraram bens passíveis de penhora. Em continuidade, ainda que houvesse a tentativa de diversos meios constritivos, o processo inevitavelmente foi ao arquivo provisório com fulcro no art. 40 da LEF por não serem encontrados bens possíveis de satisfação do crédito.

Em ato seguinte, o juiz de ofício ou até a Fazenda Pública reconheceu a prescrição intercorrente dos créditos tributários e pediu a extinção do processo que foi decretada.

Dessa maneira, pergunta-se: seria crível que haja condenaçãoda Fazenda Pública em sede de honorários advocatícios pela aplicação do princípio da causalidade, visto que a União teria movimentado o Judiciário de maneira irresponsável e teria dado causa à própria derrota?

De início, é importante refletir que a matéria - condenação em honorários - é regida por dois pontos fulcrais, notoriamente, os princípios da causalidade e da sucumbência.

Neste sentido, Cândido Rangel Dinamarco (2020, p.192) ensina:

O processo deve propiciar a quem tem razão a mesma situação econômica que ele obteria se as obrigações alheias houvessem sido cumpridas voluntariamente ou se seus direitos houvessem sido respeitados sem a instauração de processo algum.

Em outras palavras, de acordo com o princípio da causalidade (CUNHA, 2005, p.85), a parte que deu causa à instauração do processo deve suportar as despesas dele decorrentes. A sucumbência, por sua vez, é um gravame, suportado pelo vencido no processo.

Na jurisprudência do STJ, a regra da sucumbência é condicionada à regra da causalidade:

(...)À luz do princípio da causalidade, aquele que deu causa à instauração do processo deve responder pela verba honorária de sucumbência (...)

(STJ; AgInt-AREsp 1.364.626; Proc. 2018/0183912-0; PE; Primeira Turma; Rel. Min. Gurgel de Faria; Julg. 14/05/2019; DJE 12/06/2019) 
(...)Verifica-se que a fixação, pelo Tribunal de origem, do valor dos honorários baseou-se no princípio da causalidade, visto que a recorrente deu causa ao processo. Modificar tal entendimento esbarra no óbice do enunciado da Súmula $\mathrm{n}^{\circ} 7$ do STJ. 2. Recurso Especial não conhecido.

(STJ; REsp 1.811.120; Proc. 2019/0074110-0; SP; Segunda Turma; Rel. Min. Herman Benjamin; Julg. 11/06/2019; DJE 17/06/2019)

(...)A desistência da execução em virtude da não localização de bens do devedor não retira a aplicação do princípio da causalidade em desfavor do executado, nem atrai a sucumbência para o exequente. 3. Agravo interno a que se nega provimento.

(STJ; AgInt-REsp 1.744.492; Proc. 2018/0129729-3; PR; Quarta Turma; Rel ${ }^{\mathrm{a}}$ Min ${ }^{a}$ Maria Isabel Gallotti; Julg. 11/06/2019; DJE 14/06/2019)

Dessa forma, a leitura que se faz do artigo $82, \S 2^{\circ}$, e 85 , ambos do Código de Processo Civil de 2015, segundo os quais o vencido pagará ao vencedor as despesas que antecipou e os honorários advocatícios, trata-se do chamado Princípio da Sucumbência. Porém, da doutrina e jurisprudência extrai-se a afirmação de que a causalidade é o postulado maior, sendo a sucumbência uma mera aplicação específica, mas não a única.

Neste sentido, Yussef Said Cahali (1997, p.56)aduz que o só princípio da sucumbência não se mostra suficiente para disciplinar a responsabilidade dos encargos em um sem número de situações concretas.

Dessa forma, seria uma grande generalização, afirmar que as despesas processuais serão pagas pelo vencido ao vencedor da demanda. É bem verdade, com efeito, que, na maioria das vezes, é isso que realmente ocorre, pois, o sucumbente geralmente é aquele que deu causa à instauração do processo, mas a recíproca nem sempre é verdadeira (AZEVUM, 2019).

Assim, no nosso exemplo hipotético, percebe-se que o devedor contribuinte deixou de praticar um ato, qual seja, o dever fundamental de pagar tributos ao não adimplir a obrigação, dando causa ao ajuizamento de uma demanda (execução fiscal), devendo arcar, caso seja legítima a obrigação tributária, com os gastos do processo - despesas processuais e honorários advocatícios. Logo, não haveria azo para condenar a Fazenda Pública diante de um reconhecimento de ofício da prescrição intercorrente, pois foi ocasionado, em suma, por um ato do devedor. 
Inclusive, antes de ingressar no mérito de quem deu causa ao processo ou à ocorrência da prescrição intercorrente, cumpre frisar que a prescrição decorre do decurso do tempo em função da inexistência de bens penhoráveis, não se registrando a inação da exequente.

Noutras palavras, não há dolo ou culpa, por parte da Administração Pública, tanto que o REsp 1.340.553/SP delineou que são condições objetivas e alternativas para que haja a ocorrência do fenômeno da prescrição intercorrente.

Ademais, do ponto de vista da lisura que deve marcar a litigância judicial, a boa-fé processual e a lealdade devem estar previstas para todos os atores jurídicos.

De fato, a questão descortina um futuro problema grave, vinculado à tentativa de cobrança de honorários, onde inexistentes, cogitando-se ou estimulando a possibilidade do executado ocultar o patrimônio e, posteriormente, invocar reconhecimento de prescrição intercorrente.

Logo, tratando-se a prescrição intercorrente de instituto que se opera em face de execuções frustradas, há que se reconhecer que tal se dá por razão alheia à atuação do exequente. Não se pode nem mesmo invocar vontade da Fazenda Pública, porquanto esta, no caso, apenas protagoniza a vontade da lei. Transita-se no campo da atividade administrativa plenamente vinculada.

Assim, o cancelamento do débito, via prescrição intercorrente, é situação procedimental intrínseca e interna ao processo de execução, que não prosperou, justamente por conta do fato de que não se garantiu o juízo, dada a inexistência da penhora, ou porque não se localizou o executado devedor.

Em suma, deve-se reconhecer que o executado fora quem dera causa ao processo bem assim à extinção, por não ter pago, oferecido bens à penhora ou por tê-los sonegado.

Consequentemente, não se pode conceber a condenação em honorários, em favor do advogado do executado, especialmente se a penhora sequer chegou a ser implementada, por falta de bens penhoráveis, pois tal fundamento contraria o princípio da causalidade. 
Nessa linha, eventual condenação da Fazenda Pública em honorários advocatícios, nesse caso hipotético, traduziria uma mutilação dos princípios de justiça e materialização de pauta de subversão de valores processuais e instrumentais.

Perceba: o ajuizamento da execução fiscal dá-se, em regra, com base em dívida regularmente inscrita, marcada por presunção iuris tantum, em desfavor do executado (vide Art. 2 da Lei 6.830/1980).

Bem entendido, a suspensão do processo, e mesmo sua extinção, ocorre porque não foram encontrados bens que pudessem garantir a execução, ou nem mesmo o devedor; esta última, por essa razão, não prosperou. Assim, o executado não se defendeu porque não tinha bens ea prescrição intercorrente já o aproveitou.

Como se demonstra, não pode o devedor se beneficiar do fato de quem não pode garantir a execução, postulando honorários da União, que não deu causa ao processo.Até porque, o ajuizamento da ação de execução fisscal é desdobramento natural da inscrição em dívida ativa, a qual decorre também de ato plenamente vinculado.

Noutros termos, para haver condenação em honorários advocatícios, deve-se, primordialmente, indagar de quem deu causa à judicialização da questão.

Logo, o pano de fundo conceitual do princípio da causalidade, aplicável no presente caso, radica, de alguma forma, na compreensão de que a conduta do agente deve ser determinante à ocorrência do dano (CAHALI, 1997, p.57).

Em sentido semelhante, é o débito fiscal originário que substancializa a inscrição em dívida ativa (art.202 do CTN) e a execução fiscal, pelo que, do ponto de vista da causalidade, o ônus é do executado, e não do exequente.

De tal modo, comprovado que a demanda decorre de dívida administrativamente reconhecida e, portanto, conhecendo-se que o causador da discussão é o executado, impede-se o pagamento de honorários em desfavor da Administração Pública. 
Outrossim, adiante-se nossa concordância à decisão do STJ, versando sobre prescrição intercorrente no âmbito da cobrança de créditos privados, divulgado no informativo 646 do STJ através do REsp 1769201/SP, Rel. Ministra Maria Isabel Galotti, julgado pela $4^{\text {a }}$ Turma em $12 / 03 / 2019$.

Isto porque, nesse julgado, a $4^{\mathrm{a}}$ Turma do STJ, considerou que declarada a prescrição intercorrente por ausência de localização de bens, seria incabível a fixação de verba honorária em favor do executado, justamente porque diante dos princípios da efetividade do processo, da boa-fé processual e da cooperação, não pode o devedor se beneficiar do não-cumprimento de sua obrigação.

Assim, o reconhecimento de ofício da prescrição intercorrente por parte da Fazenda Pública, tem como resultado a impossibilidade de condenação em honorários em desfavor da Administração Pública.

A medida desafoga o processo, evita gargalos procedimentais, confere ganho de escala à atividade pretoriana, efetivamente colaborando na construção de um modelo processual mais eficiente e instrumental ${ }^{7}$.

De fato, a Procuradoria-Geral da Fazenda Nacional no relatório "PGFN em Números 2019”, demonstra que a recuperação de ativos alcançou o montante de R 24,4 bilhões,resultado que reflete o contínuo aprimoramento de estratégias qualitativas decobrança desenvolvidas (PROCURADORIA GERAL DA FAZENDA NACIONAL, 2020):

Vale a comparação: em 2016 a PGFN recuperou R\$ 14,5 bilhões.

Em 2017, foram recuperados R\$26,1 bilhões, montante que teve o impacto do último REFIS, o PERT.

Em 2018, foram recuperados $\mathrm{R} \$ 23,88$ bilhões, número que mostra que a capacidade de recuperação da dívida efetivamente mudou de patamar, o que se confirma pelo volume ainda maior de 2019 , ora divulgado.

Ora, cita-se como medidas que efetivamente ajudam na diminuição da Crise da Justiça a desistência da Fazenda Nacional de mais de 3.000 (três mil) recursos perante o $\mathrm{STJ}^{8}$, bem como

\footnotetext{
${ }^{7}$ Saliente-se, ainda, que, a atuação da Procuradoria-Geral da Fazenda Nacional em matéria como a presente, é tratada no contexto do art. 19 da Lei $n^{\circ} 10.522$, de 2002, que prevê objetivamente que a PGFN está autorizada a não contestar, a não interpor recurso ou a desistir do que tenha sido interposto, hipótese em que não haverá condenação em honorários advocatícios, justamente para estimular a redução de litigiosidade.
} 
a realização do Projeto de Depuração do Acervo $^{9}$ na Procuradoria da Fazenda Nacional de Guarulhos-SP que arquivou e reconheceu de ofício a prescrição intercorrente em mais de 2.000 (dois mil) processos judiciais pendentes.

Em síntese, seja pelo princípio da causalidade que reconhece que a via judicial foi suscitada em face do inadimplemento do devedor, não sendo justo que a Fazenda Pública arque com os honorários advocatícios quando houver o reconhecimento da prescrição intercorrente nas execuções fiscais ${ }^{10}$. Inclusive, essa visão prestigia uma análise de que não poderia o devedor, por não ter bens nem ter seu endereço atualizado, ser beneficiado pelo seu inadimplemento.

\section{CONSIDERAÇÕES FINAIS}

Em arremate: no que tange à condenação ao pagamento de honorários advocatícios, temse que foi a parte executada que deu causa à propositura da ação e não parece razoável que além de não receber o crédito que lhe cabe, seja o Ente Público ainda obrigado a pagar os honorários de sucumbência em razão da extinção da execução atingida pela prescrição intercorrente.

Noutros termos, nos casos de execução extinta pela prescrição intercorrente, o princípio da causalidade incide, portanto, em desfavor do executado, eis que ele dá causa ao pedido executório ao não efetuar o pagamento ou não cumprir a obrigação de forma espontânea.

Saliente-se que essa corrente tem respaldo na efetividade e boa-fé processual, não podendo o devedor se beneficiar do não-cumprimento de sua obrigação.

Ademais, a impossibilidade de condenação da Fazenda Pública em honorários advocatícios prestigia a colaboração e cooperação da redução da Crise da Justiça, eis que

\footnotetext{
${ }^{8}$ Inclusive, cumpre ressaltar medidas cooperativas firmadas entre o STJ e Fazenda Nacional, que já firmaram parceria para reduzir processos em tramitação, como se visualiza em:

http://www.stj.jus.br/sites/portalp/Paginas/Comunicacao/Noticias/STJ-e-Fazenda-Nacional-firmam-parceriapara-reduzir-processos-em-tramitacao.aspx. acesso em 12/10/2020.

${ }^{9}$ Vide Processo SEI 19622.1000083/2020-07 firmado em convênio com a Corregedoria do Tribunal de Justiça de São Paulo-SP.

${ }^{10}$ Inclusive, tal corrente encontra respaldo em precedentes do TRF2 ,TRF4 e TRF5:

TRF 2a R.; AC 0010623-85.2008.4.02.5001; Oitava Turma Especializada; Rel. Des. Fed. Marcelo Pereira da Silva; Julg. 30/04/2019; DEJF 14/06/2019

TRF 4a R.; AC 5027655-53.2018.4.04.9999; Segunda Turma; Rel. Juiz Fed. Alcides Vettorazzi; Julg.

TRF 5 ${ }^{\mathrm{a}}$ R.; AC 2007.81.00.002775-5; CE; Quarta Turma; Rel. Des. Fed. Edilson Pereira Nobre Júnior; Julg. 21/05/2019; DEJF 27/05/2019; Pág. 52
} 
estimula que o Ente Público busque o reconhecimento da prescrição intercorrente de ofício, reduzindo a litigiosidade, como no projeto de Depuração de Acervo firmado perante o TJSP e em curso pela Procuradoria Regional da Fazenda Nacional da $3^{\text {a }}$ Região.

\section{REFERENCIA}

ARRUDA ALVIM WAMBIER, Teresa; CONCEIÇÃO, Maria Lúcia Lins; RIBEIRO, Leonardo Ferres da Silva;MELLO, Rogério Licastro Torres de. Primeiros comentários ao novo Código de Processo Civil artigo por artigo. 2. ed. São Paulo: Ed. RT, 2016.

AVEZUM, Luís Renato. Princípio da causalidade x princípio da sucumbência: a necessária distinção para a necessária complementação. Disponível em: https:/emporiododireito.com.br/leitura/principio-da-causalidade-X-principio-da-sucumbencia-anecessaria-distincao-para-a-necessaria-complementacao-1. Acesso em: 09 set. 2020.

BRASIL. Lei $\mathrm{n}^{\mathbf{0}} \mathbf{1 0 . 4 0 6}$, de 10 de janeiro de 2002. Institui o código civil. Disponível em:http://www.planalto.gov.br/ccivil_03/leis/2002/110406compilada.htm. Acesso em: 09 set. 2020 .

BRASIL. Lei $\mathrm{n}^{\circ} \mathbf{1 3 . 1 0 5}$ de 16 de março de 2015. Institui o novo código de processo civil. Disponível em: http://www.planalto.gov.br/ccivil_03/_ato2015-2018/2015/lei/113105.htm: Acesso em: 09 set. 2020.

BRITO, Thiago Souza; FERNANDES, Rodrigo Saldanha. Inteligência Artificial e a Crise do Poder Judiciário: Linhas Introdutórias sobre a Experiência Norte-Americana, Brasileira e sua Aplicação no Direito Brasileiro. Revista Acadêmica da Faculdade de Direito do Recife, Recife, v.91, n.2, p. 84-107,set. 2020. ISSN 2448-2307.

BUENO,Cassio Scarpinella. Curso sistematizado de direito processual civil: Tutela Jurisdicional Executiva. 7. ed., rev. e atual. São Paulo: Saraiva, 2014.v. 3.

BUENO, Cassio Scarpinella. Manual de direito processual civil. 2.ed. São Paulo: Saraiva, 2016.Versão digital.

CÂMARA, Alexandre Freitas. O novo processo civil brasileiro. São Paulo: Atlas, 2015.

CÂMARA, Alexandre Freitas. O Novo Processo Civil brasileiro. São Paulo: Editora Forense Ltda, 2016.

CARVALHO. Paulo de Barros. Curso de direito Tributário. 18. ed. ver.e atual. São Paulo: Saraiva, 19--?

CAVALCANTE, Márcio André Lopes. Forma de contagem do prazo da prescrição intercorrente prevista no art. 40, da LEF. Buscador Dizer o Direito, Manaus. Disponível em:https://www.buscadordizerodireito.com.br/jurisprudencia/detalhes/63d5fb54a858dd033fe90e 6e4a74b0f0. Acesso em: 12 out. 2020.

CNJ. Justiça em Números 2020, ano-base 2019. Disponível em: https://www.cnj.jus.br/wpcontent/uploads/2020/08/WEB-V3-Justi\%C3\%A7a-em-N\%C3\%BAmeros-2020-atualizado-em25-08-2020.pdf. Acesso em: 12 out. 2020. 
CUNHA, Leonardo Carneiro da.A Fazenda Pública em juízo.14. ed. rev., atual e ampl. Rio de Janeiro: Forense, 2017.

CUNHA, Leonardo Carneiro da. Comentários ao art. $8^{\circ} . I n$ : CUNHA, Leonardo Carneiro da; STRECK, Lenio Luiz; NUNES, Dierle; FREIRE, Alexandre (coord). Comentários ao código de processo civil. São Paulo: Saraiva, 2016.

CUNHA, Leonardo Carneiro da; DIDIER JR., Fredie. Curso de direito processual civil. 13. ed. Salvador: Juspodivm, 2015.v. 3.

CUNHA, Leonardo Carneiro da; DIDIER JR., Fredie. Honorários de sucumbência e princípio da causalidade. Revista Dialética de Direito Processual, São Paulo, v. 23, p. 85-94, 2005.

DE LIMA, Antonio Sebastião. Crise da Justiça. Revista da EMERJ, v.9, n.36, 2006. Disponível em: https://www.emerj.tjrj.jus.br/revistaemerj_online/edicoes/revista36/revista36_271.pdf. Acesso em:12 out. 2020.

DIDIER JR., Fredie; BRAGA, Paula Sarno; OLIVEIRA, Rafael. Curso de direito processual civil. 11. ed. Salvador: Juspodivm, 2016. v. 2.

DINAMARCO, Cândido Rangel. Instituições de Direito Processual Civil. 10.ed. Salvador: Jupodivm. 2020.v.2.

FRANCO, Marcelo. A crise da justiça como um problema cultural e administrativo-gerencial. Revista Acadêmica da Faculdade de Direito do Recife, Recife, v.83, n. 1, 2011.Disponível em: https://periodicos.ufpe.br/revistas/ACADEMICA/article/view/296/265. Acesso em:12 out. 2020 .

INSTITUTO DE PESQUISA ECONÔMICA APLICADA. Custo e Tempo do Processo de Execução Fiscal Promovido pela Procuradoria-Geral da Fazenda Nacional. Brasília/DF: IPEA, 2011.

JOTA.Fazenda desistirá de 3 mil recursos no STJ. Disponível em: https://www.jota.info/tributos-e-empresas/tributario/stj-fazenda-creditos-irrecuperaveis31052019.Acesso em: 12 out. 2020.

MEDINA, José Miguel Garcia. Novo código de processo civil comentado. 4.ed. São Paulo: RT, 2016.

MURPHY, Liam; NAGEL, Thomas. O mito da propriedade: os impostos e a justiça. Tradução: Marcelo Brandão Cipolla. São Paulo: Martins Fontes, 2005.

PAULSEN, Leandro. Curso de direito tributário completo.8.ed.São Paulo: Saraiva, 2017.

PEIXOTO, Daniel Monteiro. Prescrição Intercorrente na Execução Fiscal: Vertentes do STJ e as Inovações da lei n. 11.051/2004 e da Lei Complementar n. 118/2005. Revista Dialética de Direito tributário, São Paulo, n. 125, 2016.

PIKETTY, Thomas. Capital in the Twenty-First Century. Tradução: Arthur Goldhammer. Cambrigde, EUA: The Belknap Press of Harvard University Press, 2014. 
BRASIL. Procuradoria Geral da Fazenda Nacional. PGFN em Números: 2019. Brasília/DF: PGFN, 2020. Disponível em: https://www.gov.br/pgfn/pt-br/acesso-ainformacao/institucional/pgfn-em-numeros-2014/pgfn-em-numeros-2020/view. Acesso em: 12 out. 2020.

SUNSTEIN, Cass R; HOLMES, Stephen. El Costo de losderechos: Por quélalibertadad depende de losimpuestos. Tradução: Stella Mastrangelo. Buenos Aires: SigloVeintiuno, 2012.

WAMBIER, Teresa Arruda Alvim et al.Primeiros comentários ao novo código de processo civil: artigo por artigo. São Paulo: Revista dos Tribunais, 2015. 